\title{
CAUSAS ESTRUTURAIS E CONSEQUÊNCIAS DOS REGIMES INTERNACIONAIS: REGIMES COMO VARIÁVEIS INTERVENIENTES ${ }^{1}$
}

\author{
Stephen D. Krasner
}

\begin{abstract}
RESUMO
Os regimes internacionais são definidos como princípios, normas, regras e procedimentos de tomada de decisões ao redor dos quais as expectativas dos atores convergem em uma dada área-tema. Como ponto de partida, os regimes são conceituados como variáveis intervenientes, estando entre fatores causais básicos e os resultados e comportamentos relacionados. Há três visões a respeito da importância dos regimes: as orientações estruturais convencionais desvalorizam os regimes como sendo, na melhor das hipóteses, ineficazes; as orientações grocianas vêem os regimes como componentes intimos do sistema internacional; as perspectivas estruturalistas modificadas vêem os regimes como significativos somente em certas condições restritas. Para os argumentos grociano e estruturalista modificado - que concordam com a visão de que os regimes podem influenciar resultados e comportamentos-, o desenvolvimento de regimes é visto como uma função de cinco variáveis causais básicas: auto-interesse egoista; poder político; normas e princípios difusos; usos e costumes; conhecimento.
\end{abstract}

PALAVRAS-CHAVE: regimes internacionais; variáveis intervenientes; comportamento; grocianismo; estruturalismo modificado.

\section{INTRODUÇÃO}

Este volume ${ }^{2}$ explora o conceito de regimes internacionais. Os regimes internacionais são definidos como princípios, normas, regras e procedimentos de tomada de decisões de determinada área das relações internacionais em torno dos quais convergem as expectativas dos atores. Como um ponto de partida, os regimes têm sido conceituados como variáveis intervenientes entre os fatores causais básicos, de um lado, e resultados e comportamentos, de outro. Essa formulação gera duas questões básicas: em primeiro lugar, qual é a relação entre os fatores causais básicos, tais como poder, interesse e valores e os regimes? Em segundo lugar, qual é a relação entre os regimes e os resultados e comportamentos correlatos? A primeira pergunta está relacionada a certos debates

${ }^{1}$ Artigo publicado originalmente sob o título "Structural Causes and Regime Consequences: Regimes as Intervening Variables", na revista International Organization (Cambridge (MA), v. 36, n. 2, p. 185-205, Spring.1982). Tradução de Dalton Guimarães, Feliciano Guimarães e Gustavo Biscaia de Lacerda. paradigmáticos sobre a natureza das relações internacionais. Mas para os propósitos deste volume a segunda pergunta é tanto ou mais importante, pois levanta a questão sobre se os regimes fazem alguma diferença.

Os artigos deste volume apresentam três abordagens para a questão do significado dos regimes. Os artigos de Oran Young (1982) e Donald Puchala e Raymond Hopkins (1982) vêem os regimes como uma característica disseminada por todo o sistema internacional. Nenhum padrão de comportamento pode sustentar-se por qualquer período de tempo sem gerar um regime compatível. Os regimes e os comportamentos são inexoravelmente imbricados. Em contraste, Susan Strange (1982) argumenta que regime é um

2 O presente artigo integra uma edição da revista International Organization que trata exclusivamente do conceito de regime internacional. O presente artigo de Stephen Krasner é a introdução da edição e seu objetivo é apresentar o conceito de regimes internacionais que será discutido pelos demais autores - daí as inúmeras referências aos outros artigos da revista (nota dos tradutores). 
conceito enganoso que obscurece as relações básicas entre economia e poder. Strange, representando provavelmente o que seria a posição mais tradicional dos pensadores das relações internacionais, elabora uma crítica estrutural convencional que rejeita qualquer papel significativo para princípios, normas, regras e procedimentos para tomada de decisões. A maioria dos autores neste volume adota uma terceira posição que pode ser classificada de "estruturalista modificada". Eles aceitam os pressupostos analíticos básicos das abordagens estruturalrealistas, as quais pressupõem um sistema internacional funcionalmente simétrico de estados maximizadores de poder agindo em um ambiente anárquico. Mas eles sustentam que sob certas condições restritas, envolvendo a falha de ações individuais para obter resultados Pareto-ótimos, os regimes internacionais podem ter um impacto significativo mesmo em um mundo anárquico. Essa orientação é elaborada mais explicitamente nos artigos de Arthur Stein (1982), Robert Keohane (1982) e Robert Jervis (1982); ela também reflete as análises de John Ruggie (1982), Charles Lipson (1982) e Benjamin Cohen (1982).

A próxima seção deste artigo desenvolve as definições de regimes e de mudanças de regime. A seção seguinte investiga diversas abordagens sobre as relações entre regimes, comportamentos e resultados. A quarta seção examina cinco fatores causais básicos - $\mathrm{o}$ auto-interesse egoísta, o poder político, as normas e princípios difusos, usos e costumes e o conhecimento - que têm sido usados para explicar o desenvolvimento dos regimes.

\section{DEFININDO REGIMES E MUDANÇAS DE REGIMES}

Os regimes podem ser definidos como princípios, normas e regras implícitos ou explícitos e procedimentos de tomada de decisões de determinada área das relações internacionais em torno dos quais convergem as expectativas dos atores. Os princípios são crenças em fatos, causas e questões morais. As normas são padrões de comportamento definidos em termos de direitos e obrigações. As regras são prescrições ou proscrições especificas para a ação. Os procedimentos para tomada de decisões são práticas predominantes para fazer e executar a decisão coletiva.
Esse uso do conceito é consistente com outras formulações recentes. Keohane e Nye (1977, p. 19), por exemplo, definem os regimes como "conjuntos de arranjos de governança" que incluem "redes de regras, normas e procedimentos que regulam comportamentos doa atores e controlam os seus efeitos". Haas (1980b, p. 553) argumenta que o regime engloba um conjunto mutuamente coerente de procedimentos, regras e normas. Hedley Bull (1977, p. 54), usando uma terminologia um pouco diferente, ao referirse à importância das regras e instituições na sociedade internacional, sustenta que as regras são "princípios gerais imperativos que requerem ou autorizam determinadas classes de pessoas ou grupos a comportar-se das maneiras prescritas". Para Bull as instituições ajudam a assegurar adesão às regras por meio da formulação, da comunicação, da administração, da imposição, da interpretação, da legitimação e da adaptação dessas regras.

Os regimes precisam ser entendidos como algo mais do que arranjos temporários que mudam com cada alteração de poder ou interesses dos estados. Keohane sustenta que uma distinção analítica básica precisa ser feita entre regimes e acordos. Os acordos são arranjos ad hoc, geralmente únicos e de curta duração. O propósito dos regimes, por sua vez, é facilitar os acordos. Da mesma forma, Jervis argumenta que o conceito de regimes "não implica apenas normas e expectativas que facilitam a cooperação, mas uma forma de cooperação que é mais do que atender o próprio egoísta de curto prazo" (JERVIS, 1982, p. 357). Por exemplo, ele sustenta que as restrições aplicadas na Guerra da Coréia e em outras guerras específicas não deveriam ser consideradas como um regime. Tais regras, como "não bombardear santuários", foram baseadas puramente em avaliações de interesse de curto prazo. Como os interesses e o poder mudaram, o comportamento também mudou. $\mathrm{O}$ conceito de equilíbrio de poder de Waltz, em que a ação dos estados é dirigida por pressões sistêmicas no sentido de estabelecer repetidamente o equilíbrio, não é um regime; a concepção de Kaplan, em que o equilíbrio requer o comprometimento dos estados com regras que restringem a maximização imediata de poder no curto prazo (especialmente não destruindo um ator essencial) é um regime (KAPLAN, 1957, p. 23; 1979, p. 66-69, 73; WALTZ, 1979). 
De modo similar, o comportamento definido pelo regime não pode ser baseado apenas em cálculos de interesse de curto prazo. Como os regimes abrangem princípios e normas, a função de utilidade que está sendo maximizada precisa incorporar algum sentido de obrigação geral. Um princípio como esse - a reciprocidade - é enfatizado na análise de Jervis (1982, p. 357) sobre regimes de segurança. Quando os estados aceitam a reciprocidade eles sacrificam os interesses de curto prazo na expectativa de que os outros atores retribuam esse sacrifício no futuro, mesmo que eles não sejam obrigados a fazê-lo por uma norma específica. Essa formulação é similar à brilhante discussão de Fred Hirsch sobre amizade, em que ele diz: "A amizade possui um elemento de troca mútua direta e nesse sentido assemelha-se a um bem econômico privado. Mas geralmente é muito mais do que isso. Ao longo do tempo, a 'transação' de amizade pode ser presumida, dada a sua permanência, como um beneficio para ambos os lados. A qualquer momento, contudo, é bastante improvável que a troca esteja equilibrada de maneira recíproca" (HIRSCH, 1976, p. 78). É a mistura de comportamentos com princípios e normas que distingue as ações estatais governadas por regimes da atividade mais convencional guiada exclusivamente pela estreita avaliação de interesses.

Uma distinção fundamental precisa ser feita entre princípios e normas, por um lado, e regras e procedimentos, por outro lado. Os princípios e as normas fornecem as características básicas definidoras de um regime. Podem existir muitas regras e procedimentos de tomada de decisão que são consistentes com os mesmos princípios e normas. Assim, mudanças em regras e procedimentos de tomada de decisão são mudanças internas aos regimes, desde que os princípios e as normas não sejam alterados. Por exemplo, Benjamin Cohen (1982) mostra que houve um aumento substancial de financiamento por bancos privados durante os anos 1970. Isso significou uma alteração nas regras de ajuste da balança de pagamento, mas não uma mudança fundamental no regime. A norma básica do regime se manteve a mesma: o acesso a financiamentos para a balança de pagamentos deve ser controlado e condicionado pelo comportamento dos países tomadores de empréstimos. John Ruggie argumenta que em geral as alterações em regimes econômicos internacionais que ocorreram nos anos 1970 foram mudanças controladas pelas normas [norm-governed changes]. Elas não alteraram os princípios básicos e as normas incorporados nos regimes liberais e em uso desde os anos 1940.

As mudanças em princípios e normas são mudanças do próprio regime. Quando normas e princípios são abandonados ocorre ou uma mudança para um novo regime ou o desaparecimento dos regimes de determinada área das relações internacionais. Por exemplo, Ruggie (1982) discute que a distinção entre liberalismo ortodoxo e incrustado [embedded liberalism] envolve diferenças acerca de normas e princípios. O liberalismo ortodoxo endossa a crescente abrangência do mercado. O liberalismo incrustado prescreve ações para o Estado conter mudanças domésticas sociais e econômicas geradas pelos mercados. Os liberalismos ortodoxo e incrustado definem regimes diferentes entre si. A mudança de princípios e normas liberal-ortodoxos antes da II Guerra Mundial para princípios e normas liberal-incrustados depois da II Guerra foi, nos termos de Ruggie, "revolucionária".

Os argumentos políticos mais fundamentais estão mais relacionados a normas e princípios do que a regras e procedimentos. Mudanças nestas últimas podem ser interpretadas de diferentes maneiras. Por exemplo, na área de comércio internacional, as recentes revisões nos artigos do Acordo Geral de Tarifas e Comércio [General Agreement on Tariffs and Trade (GATT), em inglês] buscam dar tratamento especial e diferenciado aos países menos desenvolvidos (PMDs). Todos os países industrializados têm instituído sistemas de preferências comerciais para os PMDs. Essas regras violam uma das normas básicas da ordem liberal posterior à II Guerra Mundial: a cláusula da nação mais favorecida. Entretanto, as nações industrializadas trataram essas alterações das regras como mudanças temporárias necessárias, dadas as circunstâncias peculiares das áreas mais pobres. Graças à insistência estadunidense, o conceito de "gradação" foi introduzido formalmente nas cláusulas do GATT após a Rodada de Tóquio (1973-1979). A gradação dispõe que, conforme os países tornam-se mais desenvolvidos, eles aceitarão regras consistentes com os princípios liberais. Portanto, os representantes dos países desenvolvidos decidiram interpretar o tratamento 
especial e diferencial de países em desenvolvimento como mudança no interior do regime.

Os porta-vozes do Terceiro Mundo, por outro lado, argumentaram que as normas básicas da ordem econômica internacional deveriam ser a redistribuição e a eqüidade, em vez da nãodiscriminação e da eficiência. Eles viam a mudança das regras como mudanças do regime porque as identificam como alterações básicas de princípios. Existe uma diferença fundamental entre ver mudanças nas regras como indicação de mudanças dentro do regime e ver essas mudanças como indicações de mudança entre regimes. A diferença gira em torno da avaliação sobre se os princípios e as normas em si mudaram. Tais avaliações nunca são fáceis porque não podem ser baseadas em observações comportamentais objetivas. "Nós reconhecemos desvios de regimes", Ruggie declara, "não simplesmente por meio de atos que são praticados, mas pela intencionalidade e aceitabilidade atribuídas a esses atos no contexto de uma estrutura intersubjetiva de significado" (RUGGIE, 1982, p. 380).

Finalmente, é necessário distinguir o enfraquecimento de um regime de mudanças dentro do regime ou mudanças entre regimes. $\mathrm{Se}$ princípios, normas, regras e procedimentos de tomada de decisão de um regime tornam-se menos coerentes ou se as práticas correntes são crescentemente inconsistentes com os princípios, as normas, as regras e os procedimentos, um regime enfraqueceu. $\mathrm{O}$ tratamento diferencial e especial para países em desenvolvimento é uma indicação de que o regime liberal enfraqueceu, mesmo que ele não tenha sido substituído por nenhum outro. O uso de cobertura diplomática por espiões, a escuta em embaixadas, o assassinato de diplomatas por terroristas e a falha em prover proteção policial local adequada são indicações de que o clássico regime de proteção a enviados estrangeiros enfraqueceu-se. Entretanto, a natureza furtiva dessas atividades indica que os princípios básicos e as normas não estão sendo diretamente desafiados. Em contraste, o seqüestro de diplomatas estadunidenses por grupos apoiados pelo governo iraniano é um desafio central ao próprio regime. O Irã viola os princípios e as normas e não somente as regras e os procedimentos ${ }^{3}$.

Em suma, as mudanças no interior de um regime envolvem alterações de regras e procedimentos de tomada de decisões, mas não de normas ou princípios; as mudanças de regimes envolvem alteração de normas e princípios; o enfraquecimento de um regime envolve ou uma incoerência entre os componentes do regime ou uma inconsistência entre o regime e o comportamento correspondente dos membros.

\section{OS REGIMES TÊM IMPORTÂNCIA?}

Seria preciso alguma coragem - talvez mais coragem do que possuímos - para responder negativamente essa pergunta. Este projeto começou com um simples esquema causal. Esse esquema assumia que os regimes poderiam ser concebidos como variáveis intervenientes localizadas entre varáveis causais básicas (na maioria das vezes, poder e interesses) e resultados e comportamentos. Assim, a primeira tentativa de analisar os regimes tem como pressuposto o seguinte conjunto de relações causais (ver Figura 1).

FIGURA 1 - ESQUEMA CAUSAL BÁSICO DOS REGIMES

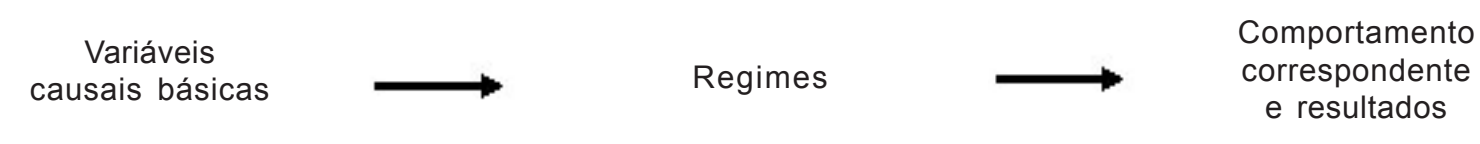

FONTE: o autor.

Os regimes não surgem por sua própria iniciativa. Eles não vistos como fins em si mesmos. Uma vez em funcionamento, eles de fato afetam os comportamentos e resultados. Eles não são meros epifenômenos.

O impacto independente ou autônomo dos regimes é uma questão analítica central. A segunda flecha causal acima significa que os regimes de fato importam. Entretanto, não há consenso a esse

\footnotetext{
3 O comportamento do Irã pode ter raízes em uma visão islâmica de relações internacionais que rejeita o regime prevalecente, de origem européia. Cf. Rosecrance (1981) para uma visão similar.
} 
respeito e três visões diferentes podem ser distinguidas. A visão estrutural convencional vê o conceito de regime como inútil, se não enganoso. A perspectiva estrutural modificada sugere que os regimes podem ter importância, mas somente sob condições muito restritas. E a visão grociana vê os regimes de uma forma bem mais disseminada, como um atributo inerente a qualquer padrão de comportamento humano complexo e persistente.

Neste volume Susan Strange (1982) representa a visão estrutural convencional. Ela tem fortes reservas quanto ao valor da noção de regime. Strange argumenta que o conceito é pernicioso porque ofusca e obscurece as relações entre poder e interesses, que são, não apenas as mais importantes, mas sobretudo as causas fundamentais do comportamento dos estados no sistema internacional. "Todos aqueles arranjos internacionais dignificados pelo rótulo de 'regime' são muito facilmente perturbados quando o equilíbrio do poder ou a percepção de interesse nacional (ou ambos em conjunto) mudam entre os estados que os negociam" (idem, p. 487). Os regimes, se é que se pode dizer que existem, têm pequeno ou nenhum impacto. Eles são meros epifenômenos. O esquema causal subjacente desta visão mostra uma conexão direta entre mudanças em fatores causais básicos (sejam políticos, sejam econômicos) e mudanças em comportamentos e resultados. Os regimes são completamente excluídos ou seu impacto nos resultados e nos comportamentos correlatos é visto como trivial.

A posição de Strange é consistente com as orientações intelectuais predominantes que analisam os fenômenos sociais. Essas orientações estruturais conceituam um mundo de atores autointeressados. Os atores podem ser indivíduos, empresas, grupos, classes ou estados. Eles agem em um sistema definido por seus próprios interesses, poder ou interações. Essa visão é resistente ao argumento de que princípios, normas, regras e procedimentos de tomada de decisões têm um impacto significativo nos resultados e comportamentos.

Essa visão é mais evidente na imagem do mercado, a concepção analítica reinante da Economia, a mais bem-sucedida das Ciências Sociais. Um mercado é caracterizado pela impessoalidade entre compradores e vendedores, pela especialização em comprar e vender e pelas trocas baseadas em preços definidos por um meio comum de troca (BELSHAW, 1965, p. 8-9). Max Weber afirma que no mercado as "ações sociais não são determinadas pela orientação de qualquer tipo de norma vista como válida, nem são elas baseadas nos costumes, mas inteiramente no fato de que o tipo correspondente de ação social está na natureza do caso adaptada o melhor possível aos interesses normais dos atores conforme eles mesmos percebem-nos" (WEBER, 1977, p. 30). O mercado é um mundo de indivíduos atomizados, auto-interessados e egoístas.

O mercado é uma metáfora poderosa para muitos argumentos na literatura da Ciência Política, para não falar das Relações Internacionais. $\mathrm{O}$ trabalho recente de Keneth Waltz (1979) exemplifica essa orientação. Para Waltz a característica definidora do sistema internacional é que as partes componentes (estados) do sistema são funcionalmente similares e interagem em um ambiente anárquico. Os sistemas internacionais distinguem-se entre si somente pela distribuição de capacidades relativas entre os atores. Presume-se que os estados agem em seu próprio interesse; no mínimo, eles "procuram a sua própria preservação e, no máximo, buscam a dominação universal" (idem, p. 118). Eles são contidos somente pela interação com outros estados no sistema. O comportamento é, portanto, uma função da distribuição de poder entre os estados e da posição particular de cada Estado no sistema. Quando a distribuição de poder altera-se, o comportamento também muda. Para Waltz, os regimes podem estar apenas pequenos passos afastados das capacidades de poder subjacentes que os sustentam (idem, especialmente cap. 5-6) ${ }^{4}$.

A segunda visão sobre regimes internacionais - a estrutural modificada - está mais claramente demonstrada nos artigos de Keohane (1982) e Stein (1982). Ambos os autores partem de uma visão realista estruturalista convencional, ou seja, um mundo de estados soberanos buscando maximizar seus interesses e poderes. Keohane postula que no sistema internacional os regimes surgem de acordos voluntários entre atores juridicamente iguais. Stein declara que "a conceituação está calcada na clássica

4 Essa visão estruturalista convencional da escola realista é análoga às análises marxistas que focam exclusivamente na tecnologia e na estrutura econômica. 
caracterização da política internacional como relações entre entidades soberanas dedicadas à sua própria autopreservação, em última instância capazes de dependerem somente de si mesmas e preparadas para recorrerem à força" (idem, p. 300; KEOHANE, 1982, p. 330).

Em um mundo de estados soberanos, a função básica dos regimes é coordenar o comportamento dos estados no sentido de alcançar os resultados desejados em áreas particulares de interesse ${ }^{5}$. Essa coordenação é atrativa sob diversas circunstâncias. Stein e Keohane postulam que os regimes podem ter impacto quando resultados Pareto-ótimos não poderiam ser alcançados por meio de ações individuais não coordenadas. $\mathrm{O}$ dilema do prisioneiro é um exemplo clássico dessa situação na teoria dos jogos. Stein também argumenta que os regimes podem ter um efeito autônomo sobre os resultados quando o comportamento puramente autônomo leva a resultados desastrosos para ambos os lados. $\mathrm{O}$ jogo da galinha é um exemplo da teoria dos jogos análogo ${ }^{6}$. Haas (1982) e outros sugerem nesta edição que os regimes podem ter um impacto significativo em um mundo altamente complexo em que os cálculos de interesse individualista $a d$ hoc não poderiam prover o nível necessário de coordenação. Se existe um movimento geral em direção a um mundo de interdependência complexa, como tantos argumentam, o número de áreas temáticas em que os regimes podem ter importância está aumentando.

Entretanto, os regimes não podem ser relevantes em situações de soma zero nas quais os estados agem para maximizar as diferenças entre a sua utilidade e as utilidades dos demais estados. Jervis (1982) mostra a escassez de regimes na área de segurança, a qual se aproxima mais de jogos de soma zero do que as áreas econômicas. Puras motivações de poder impedem a constituição de regimes. Portanto, a segunda orientação, o estruturalismo modificado, vê os regimes emergindo e tendo um impacto significativo mas somente sob condições restritas. Essa visão sugere que o primeiro esquema siga as relações da Figura 2.

\section{FIGURA2 - REGIMES PARAA VISÃO ESTRUTURALISTAMODIFICADA}

b

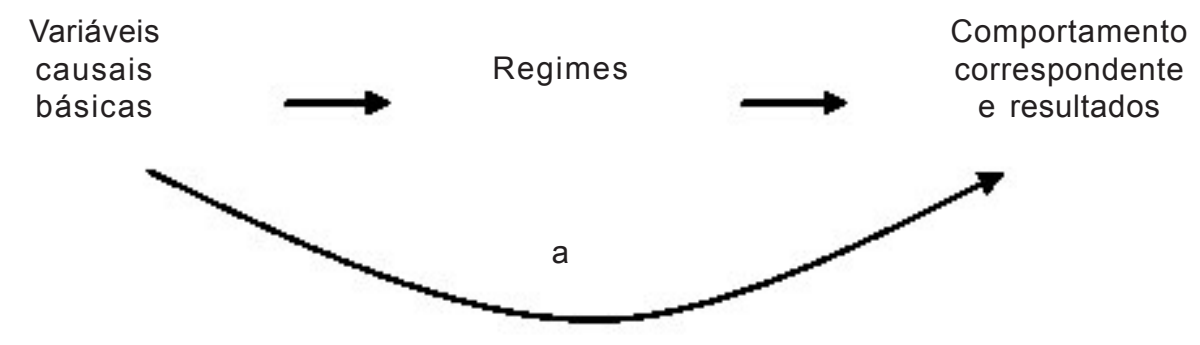

FONTE: o autor.

Na maioria das situações existe uma ligação direta entre as varáveis causais básicas e o comportamento correspondente (caminho a); mas

\footnotetext{
5 Vinod K. Aggarwal (1981, cap. 1) enfatiza esse ponto.

6 O "jogo da galinha" (game of chicken), ou "jogo do falcão e da pomba" (hawk-dove game), consiste no seguinte. Dois atores, armados, mantêm-se em rota de colisão, ao mesmo tempo em que um espera que o outro fraqueje ou capitule. O pior cenário possível, evidentemente, é quando nenhum dos dois capitula, pois ambos perdem; no caso de um dos dois capitular, será tachado de "covarde" ou "perdedor" (ou, em inglês,
}

sob certas circunstâncias não puramente conflituosas, em que a tomada de decisão individual leva a resultados sub-ótimos, os regimes podem ser importantes (caminho b) ${ }^{7}$.

"chicken"). Um exemplo concreto desse "jogo" ocorreu na Crise dos Mísseis de Cuba, em 1962 (N. T.).

7 Os argumentos estruturalistas modificados apresentados nesta edição são baseados em análises realistas das relações internacionais. Essa visão tem paralelo com muitos escritos marxistas estruturalistas que enfatizam a importância do Estado e da ideologia como instituições que agem para racionalizar e legitimar as estruturas econômicas fundamentais. 
A terceira abordagem sobre os regimes, mais claramente elaborada nos artigos de Donald Puchala e Raymond Hopkins (1982) e Oran Young (1982), reflete uma visão fundamentalmente diferente das relações internacionais dos dois argumentos estruturais descritos acima. Esses dois artigos são fortemente informados pela tradição grociana, a qual vê regimes como fenômenos disseminados em todos os sistemas políticos. Puchala e Hopkins concluem que os "regimes existem em todas as áreas temáticas, mesmo naquelas em que há grande rivalidade de poder, vistas tradicionalmente como exemplos nítidos de anarquia. Os estadistas quase sempre se sentem restringidos por princípios, normas e regras que prescrevem e proscrevem diferentes comportamentos" (PUCHALA \& HOPKINS, 1982, p. 270). Os autores argumentam que o conceito de regime vai além da perspectiva realista, a qual é "bastante limitada para explicar um mundo crescentemente complexo, interdependente e perigoso" (idem, p. 245). Puchala e Hopkins utilizam seu argumento não apenas em uma área específica das relações internacionais em que alguém poderia esperar certa comunhão de interesse (distribuição de alimentos), mas também em áreas geralmente tidas como muito mais conflitantes e ambíguas (colonialismo).

Oran Young argumenta que o comportamento padronizado inevitavelmente gera expectativas convergentes. Isso leva a um comportamento que se torna convencional, criando expectativas de que haja repreensão a desvios das práticas em uso. O comportamento convencional gera normas reconhecidas. Se o observador encontra um padrão de atividades inter-relacionadas e as conexões desse padrão são compreendidas, deve existir algum tipo de normas e procedimentos em funcionamento.

Enquanto a abordagem estrutural modificada não percebe o mercado como um regime - pois nesse caso a ação dos atores resulta puramente de cálculos individuais sem considerar o comportamento alheio -, a terceira abordagem considera de fato o mercado como um regime. Os padrões de comportamento que persistem por longos períodos de tempo estão impregnados por um significado normativo. Um mercado não pode ser mantido somente por cálculos autointeressados. Conforme os termos de Ruggie (1982), o mercado precisa estar impregnado por um ambiente social mais amplo que alimenta e sustenta as condições necessárias para o seu funcionamento. Mesmo o equilíbrio de poder, considerado pelos autores realistas estruturais convencionais como uma situação puramente conflituosa, pode ser tratado como um regime (BULL, 1977, cap. 5). O esquema causal de orientação grociana ou é parecido com o primeiro esquema causal mostrado na Figura 1 ou pode ser descrito na Figura 3 abaixo.

\section{FIGURA 3 - REGIMES PARAA ORIENTAÇÃO GROCIANA}

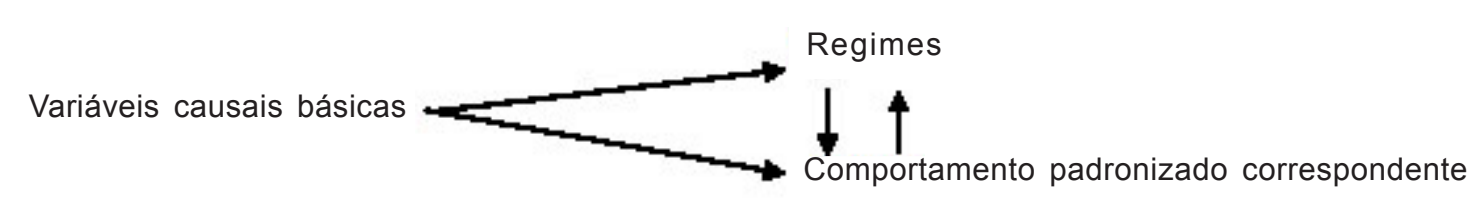

FONTE: o autor.

Os padrões de comportamentos que refletem conjecturas de interesse tendem a levar à criação de regimes internacionais, e os regimes tendem a acentuar estes comportamentos.

A tradição grociana na qual se baseiam Puchala, Hopkins e Young oferece uma contraposição às visões realistas estrutural e estrutural modificada. Esses autores rejeitam o pressuposto segundo o qual sistema internacional é composto por estados soberanos limitados apenas pelo equilíbrio de poder. Pelo contrário, Hopkins e Puchala sugerem que as elites são os atores reais das relações internacionais. Os estados são abstrações rarefeitas. As elites possuem laços tanto transnacionais quanto nacionais. A soberania é uma variável comportamental e não uma presunção analítica. A habilidade dos estados em controlar as movimentações através de suas fronteiras e manter o domínio sobre todos os aspectos do sistema internacional é limitada. A segurança e a 
sobrevivência do Estado não são os seus únicos objetivos. A força não ocupa uma posição singularmente importante na política internacional. As elites agem no interior de uma rede de comunicações, incorporando regras, normas e princípios, que transcendem as fronteiras nacionais.

Essa orientação grociana minimalista configurou uma série de postulados teóricos desenvolvidos no período posterior à II Guerra Mundial. O funcionalismo viu a possibilidade de erodir a soberania por meio da multiplicação de interesses particulares que cruzam as fronteiras nacionais. O estudo de Karl Deutsch de 1957 sobre integração, com sua ênfase na comunicação societal, fez uma distinção entre as comunidades de segurança e a anarquia ${ }^{8}$. Alguns autores associados ao conceito de transnacionalismo têm defendido a existência de uma teia de interdependência no sistema internacional, fazendo que qualquer ênfase na soberania seja analiticamente enganosa e normativamente questionável. A discussão de Keohane e Nye sobre a interdependência complexa rejeita os pressupostos de prevalência da força e de hierarquia de temas assumidos pela perspectiva realista (KEOHANE \& NYE, 1977, especialmente cap. 8). Ernest Haas indica que aquilo que ele chama de "teorias orgânicas" - ecoambientalismo, eco-reformismo e igualitarismo negam os pressupostos convencionais orientados pelo poder.

Os regimes são muito mais bem abarcados por uma visão grociana. Contudo, como indicam Cohen (1982), Jervis (1982), Keohane (1982), Lipson (1982) e Stein (1982), o conceito não é rejeitado pela perspectiva realista. A questão não é tanto se alguém aceita a possibilidade de princípios, normas, regras e procedimentos de tomada de decisão afetarem resultados e comportamentos, porém, sim, qual é o pressuposto básico a respeito da situação normal do sistema internacional. Os adeptos da perspectiva grociana aceitam os regimes como um fenômeno disseminado e significativo do sistema internacional. Já os adeptos da visão realista estrutural vêem os regimes como um fenômeno cuja presença não pode ser presumida

8 Cf. Lijphart (1974, p. 64-65) para o desenvolvimento desse argumento. e cuja existência requer uma explicação cuidadosa. Os dois "casos-padrão" são fundamentalmente diferentes e é a definição desses casos que indica a orientação teórica básica. Stephen Toulmin escreve que "qualquer teoria dinâmica envolve alguma referência implícita ou explícita a algum caso padrão ou 'paradigma'. Esse paradigma especifica a maneira como, no curso dos eventos, espera-se que corpos movam-se". É o desvio desse movimento que precisa ser explicado (TOULMIN, 1961, p. 56-57) ${ }^{9}$. De uma perspectiva realista, os regimes são fenômenos que precisam ser explicados; de uma perspectiva grociana, eles são dados a serem descritos.

Em suma, os argumentos estruturais convencionais não levam os regimes a sério: se as variáveis causais básicas mudam, os regimes também mudam. Os regimes não têm impacto independente ou autônomo sobre o comportamento. Os argumentos estruturalmodificados, aqui representados por vários adeptos da abordagem realista das relações internacionais, vêem os regimes como importantes somente quando uma tomada independente de decisão leva a um resultado indesejado. Finalmente, a perspectiva grociana aceita os regimes como uma parte fundamental de toda interação humana padronizada, incluindo os comportamentos no sistema internacional.

\section{EXPLICAÇÕES PARA O DESENVOLVI- \\ MENTO DE REGIMES}

Para aqueles autores que vêem os regimes como algo mais do que meros epifenômenos, a segunda maior questão colocada pelo esquema que vê os regimes como variáveis intervenientes entre fatores causais básicos e resultados tornase relevante. Qual é a relação entre os fatores causais básicos e os regimes? Quais são as condições que levam à criação, à permanência e à dissolução dos regimes? Nesses casos os regimes são tratados como variáveis dependentes.

Uma ampla variedade de variáveis causais básicas tem sido apresentada para explicar o desenvolvimento de regimes. As variáveis mais importantes elencadas neste volume são 1) o autointeresse egoísta, 2) o poder político, 3 ) as normas e os princípios, 4) usos e costumes e 5) o

9 O uso feito por Toulmin da palavra "paradigma" é similar à noção de Kuhn (cf. KUHN, 1970, p. 187). 
conhecimento. As duas últimas são vistas como suplementares, encorpando forças mais básicas relativas a interesse, poder e valores.

\section{IV.1. Auto-interesse egoísta}

A explicação predominante para a existência de regimes internacionais é o auto-interesse egoísta. Por "auto-interesse egoísta" eu entendo o desejo de um ator maximizar sua função de utilidade sem incluir a utilidade de outro. $\mathrm{O}$ ator egoísta preocupa-se com o comportamento de outros apenas quando o comportamento dos demais afeta a sua própria utilidade. Todas as teorias contratualistas de Hobbes a Rawls baseiamse na idéia do auto-interesse egoísta. Em contraste, um ator que busca o puro poder está interessado em maximizar a diferença entre as suas capacidades de poder e as de seus oponentes.

Neste volume, os artigos de Keohane e, especialmente, Stein adotam e elaboram, quase exclusivamente, uma perspectiva orientada pelo auto-interesse. Stein assevera que "as mesmas forças do auto-interesse elaborado de maneira autônoma que existem na raiz do sistema internacional anárquico também conformam a base dos regimes internacionais, entendidos como uma forma de ordem internacional [...]. Há ocasiões em que os cálculos racionais autointeressados levam os atores a abandonar a tomada de decisões independente em favor da tomada de decisão coletiva" (STEIN, 1982, p. 316).

Stein elabora duas circunstâncias sob as quais escolhas individuais que não sofrem restrições criam incentivos para a cooperação. A primeira ocorre quando tais escolhas levam a resultados de Pareto sub-ótimos: o dilema do prisioneiro e a provisão de bens coletivos são exemplos bem conhecidos. Stein refere-se a essas ocasiões como o dilema dos interesses comuns. Sua resolução exige "colaboração", ou seja, a construção ativa de um regime que guie a tomada de decisões individuais. A tomada de decisão individual sem restrições também pode ser evitada quando leva a resultados mutuamente indesejáveis e em que a escolha de um ator é dependente da escolha feita pelo outro: o jogo da galinha é um exemplo notório. Stein refere-se a essa situação como o dilema das aversões comuns; ele pode ser solucionado por meio da "coordenação". A coordenação não precisa ser formalizada ou institucionalizada. Desde que todos concordem em dirigir do lado certo da estrada, pouco mais é necessário. (O conceito de Stein de colaboração está de acordo com a definição de regimes usada nesta edição. Não é tão claro que coordenação envolva regimes. A coordenação pode requerer somente a elaboração de regras. No entanto, se essas regras não forem informadas por princípios ou normas próximas, elas não se conformarão à definição de regimes estabelecida anteriormente.)

Enquanto Stein adota uma orientação da teoria dos jogos, Keohane utiliza critérios de teorias microeconômicas sobre falhas de mercado para examinar os dilemas do interesse comum. Ele está principalmente preocupado com a demanda por regimes, ou seja, com as condições sob as quais acordos ad hoc falham em prover resultados Pareto-ótimos. O autor sustenta que "os regimes podem produzir acordos mais facilmente se criarem estruturas que estabeleçam responsabilidades legais (mesmo que não sejam perfeitas); se melhorarem a quantidade e a qualidade das informações disponíveis para os atores, ou se reduzirem outros custos de transação, tais como o custo de organizações ou o custo de fazer compensações paralelas [side payments]" (KEOHANE, 1982, p. 338). Esses benefícios fornecidos pelos regimes tendem a exceder os custos da formação do regime e de sua manutenção quando há informação assimétrica, risco moral, desonestidade potencial ou alta complexidade temática. Adicionalmente, os custos da formação de regimes serão menores quando houver um alto nível de comunicação formal e informal entre os estados, uma condição mais provável de ser encontrada em sistemas políticos abertos que operam sob condições de independência complexa.

O auto-interesse egoísta também é visto como um determinante importante dos regimes por vários outros autores. Young (1982) argumenta que há três caminhos para a formação de regimes: o espontâneo, no qual os regimes emergem de expectativas convergentes entre várias ações individuais; o negociado, em que os regimes são formados por acordos explícitos; o imposto, no qual os regimes são inicialmente impostos sobre os atores por forças externas. Os dois primeiros são baseados em cálculos egoístas. Lipson (1982) argumenta que o padrão diferenciado de aceitação das regras liberais no regime de comércio internacional é uma função de custos diferenciados 
de ajustamento entre os diversos setores industriais; quando os custos são baixos, a concordância continuada aos princípios, normas e regras liberais é alta. Cohen sustenta que as regras da balança de pagamento dos regimes financeiros alteraram-se nos anos 1970 devido ao aumento no preço do petróleo e pela mudança no cálculo dos juros do mercado dos petrodólares. Jervis (1982) afirma que os regimes na área de segurança só serão formados quando os estados aceitarem o status quo, pois o custo da guerra é alto e o transbordamento de tais custos para outras áreas é grande. Este último ponto, que ecoa o argumento de Keohane sobre a importância da complexidade temática, é similar aos argumentos de Haas (1982) e Puchala e Hopkins (1982). Haas faz da interconectividade um elemento central da sua análise: os regimes são projetados para gerenciar a complexidade, que por sua vez aumenta com a interconectividade. De modo similar, Puchala e Hopkins sustentam que os regimes têm mais probabilidade de surgir sob condições de interdependência complexa. Assim, cálculos de auto-interesse egoísta emergem como elementos centrais na maioria dos artigos desta edição.

\section{IV.2. Poder político}

A segunda variável causal mais importante para explicar o desenvolvimento dos regimes é o poder político. Duas visões diferentes a respeito do poder podem ser destacadas. A primeira é cosmopolita e instrumental: o poder é utilizado para assegurar resultados ótimos para o sistema como um todo. Na linguagem da teoria dos jogos, o poder é usado para promover a maximização conjunta dos ganhos. É o poder a serviço do bem comum. A segunda abordagem é particularista e relacionada a objetivos específicos [consummatory]. O poder é usado para fortalecer os valores de atores específicos do sistema. Tais valores podem incluir tanto o aumento das capacidades de poder quanto a promoção de objetivos econômicos ou ainda outros objetivos. $\mathrm{Na}$ linguagem da teoria dos jogos, o poder é utilizado para maximizar os ganhos individuais. É o poder a serviço de interesses próprios.

\section{a. O poder a serviço do bem comum}

A primeira abordagem é representada por uma longa tradição da Economia clássica e neoclássica associada à provisão de bens públicos. A mão invisível era a imagem mais convincente de Adam
Smith: o bem de todos resultante do egoísmo de cada um - não poderia haver defesa mais poderosa do egoísmo. Mas Smith reconhecia ser necessário que o Estado suprisse certos bens coletivos. Isso incluía a defesa, a manutenção da ordem, níveis mínimos de bem-estar social, serviços públicos, a proteção a indústrias nascentes e a padronização de commodities ${ }^{10}$. Os economistas têm indicado a importância do Estado no estabelecimento de direitos de propriedade e no cumprimento de contratos, ou seja, para criar as condições que evitam as ações predatórias sobre o comportamento de mercado. O Estado deve criar instituições que igualam as taxas pública e privada de retorno (NORTH \& THOMAS, 1973, cap. 1; HIRSHLEIFER, 1977; WEBER, 1977, p. 336337). A análise keynesiana dá ao Estado a proeminência na administração das variáveis macroeconômicas. Devido a todos esses argumentos, o objetivo da ação do Estado é promover os interesses gerais da sociedade.

$\mathrm{O}$ economista contemporâneo que mais claramente se identificou com os argumentos que enfatizam o papel instrumental do poder com propósitos cosmopolitas no sistema internacional foi Charles Kindleberger. Na obra The World in Depression, Kindleberger argumenta que a depressão dos anos 1930 poderia ter sido evitada por uma liderança efetiva do Estado. Um líder efetivo teria agido como emprestador de última instância e criado um mercado para os bens de consumo excedentes. No período entre-guerras os Estados Unidos eram capazes mas não tinham o interesse de assumir esses custos; a GrãBretanha, embora tivesse o interesse, não era capaz. O resultado foi o caos econômico. Em uma declaração mais recente, Kindleberger listou as seguintes funções que os estados desempenham em um sistema de comércio internacional:

10 Existe um debate vigoroso sobre precisamente quanta importância Smith conferia ao Estado. Alguns (cf., por exemplo, HIRSCHMAN, 1977, p. 103-104) sustentam que Smith queria limitar as extravagâncias do governo restringindo seu papel ao mínimo possível. Outros (cf. por exemplo HOLMES, 1976, p. 673; DIAZALEJANDRO, 1978, p. 124-125) adotam a posição intermediária, esposada aqui. Ainda outros vêem Smith tentando estabelecer as condições para uma sociedade moral que deveria basear-se na escolha individual e para a qual um sistema econômico materialista mantido egoisticamente é apenas instrumental (cf. por exemplo BILLET, 1974). 
1. proteger os atores econômicos da força;

2. amortecer os efeitos indesejáveis de um sistema aberto fornecendo, por exemplo, assistência para que empresas importadoras e competitivas ajustam-se;

3. estabelecer padrões para produtos. $\mathrm{Na}$ ausência desses padrões uma energia excessiva pode ser desperdiçada ao tentar obter informações sobre os produtos;

4. fornecer uma moeda nacional que possa ser usada como reserva internacional e moeda de transação;

5. construir bens públicos como portos e sistemas de transporte domésticos e

6. compensar as imperfeições de mercado sendo, por exemplo, o emprestador de última instância quando as instituições privadas tornarem-se tão cautelosas a ponto de destruírem a liquidez global (KINDLEBERGER, 1978a) ${ }^{11}$.

A despeito de sua ênfase na ação política, a perspectiva de Kindleberger (1978b) é ainda profundamente liberal. O propósito da intervenção do Estado é facilitar a criação e a manutenção de um ambiente no qual um mercado baseado em cálculos individuais auto-interessados possa florescer. O mercado, como o corpo humano, é basicamente saudável, mas a intervenção ocasional de algum agente externo (o Estado, um médico) pode ser necessária. Uma economia de mercado maximiza a utilidade da sociedade como um todo. O poder político é colocado a serviço do bem comum.

\section{b. O poder a serviço de interesses particulares}

Os artigos desta edição são menos orientados para fins cosmopolitas e mais ligados ao poder como instrumento que pode ser utilizado para valorizar a utilidade de atores específicos, normalmente os estados. Uma analogia com a teoria dos jogos facilita a distinção entre duas variantes importantes no que diz respeito ao poder a serviço de interesses específicos. A primeira

\footnotetext{
11 Adam Smith era menos fascinado pela idéia de liderança. Ele sentia que a interação razoável somente poderia ocorrer no sistema internacional se houvesse um equilíbrio de poder. Sem tal equilíbrio o forte dominaria e exploraria o fraco (cf. DIAZ-ALEJANDRO, 1978, p. 92).
}

pressupõe que os ganhos são fixos e que a escolha da estratégia pelo ator é determinada de maneira autônoma e somente em função desses ganhos. A segunda pressupõe que o poder pode ser usado para alterar os ganhos e influenciar a estratégia do ator.

A primeira abordagem segue de perto a análise que se aplica quando objetivos puramente cosmopolitas estão em jogo, exceto pelo fato segundo o qual o poder político é utilizado para maximizar os ganhos individuais e não os ganhos comuns. Em certas configurações de interesse, há incentivos para criarem-se regimes e a provisão desses regimes é uma função da distribuição de poder. Enquanto Keohane (1982), no artigo desta edição, focaliza na demanda por regimes, em outro trabalho o autor argumentou que o ator hegemônico tem um papel crítico na provisão dos bens coletivos necessários ao funcionamento efetivo dos regimes (KEOHANE, 1980). Os atores hegemônicos fornecem tais bens não porque estejam interessados no bem-estar do sistema como um todo, mas porque os regimes fortalecem seus próprios valores nacionais.

Essa ênfase na necessidade de distribuição assimétrica de poder (considerações da economia da oferta [supply-side considerations]) deve ser confrontada com as proposições de Stein (1982) relativas à eficácia da demanda. A teoria da liderança hegemônica sugere que sob condições de hegemonia declinante haverá um enfraquecimento dos regimes. Sem a liderança, princípios, normas, regras e procedimentos para tomadas de decisão não podem ser facilmente mantidos. Nenhum ator terá o interesse em fornecer os bens coletivos necessários para fazer o regime funcionar suave e efetivamente. A análise de Stein, por outro lado, sugere que à medida que a hegemonia declina haverá maiores incentivos para colaboração, pois os bens coletivos não são mais garantidos pelo ator hegemônico. O sistema internacional parece-se mais com um oligopólio do que com um mercado perfeito. Os atores estão cientes de como seus comportamentos afetam uns aos outros. Quando estados mais fracos percebem que o ator hegemônico não está mais interessado em promover a carona [free ride], é provável que eles tornem-se clientes pagantes. Para Stein, os interesses por si sós podem manter efetivamente a ordem. O declínio hegemônico pode levar a regimes mais fortes. 
A segunda linha de argumentação associada ao poder a serviço de interesses específicos investiga a possibilidade de que atores poderosos possam ser capazes de alterar os ganhos no sentido de afrontar outros atores ou influenciar as estratégias que eles escolhem. Nesse caso, o poder torna-se um conceito muito mais central o elemento de uso da força está facilmente à mão. Os atores mais fracos podem não ser capazes de fazer escolhas autônomas. Os valores destinados a uma unidade de análise em particular podem ser alterados.

Neste volume, Oran Young (1982) desenvolve a noção de "regimes impostos". Os atores dominantes podem explicitamente usar uma combinação de sanções e incentivos para forçar outros atores a agir de acordo com um conjunto particular de princípios, normas, regras e procedimentos de tomada de decisões. Por outro lado, os atores dominantes podem assegurar a aquiescência de facto ao manipularem determinadas oportunidades, de tal modo que atores mais fracos são levados a comportaremse da maneira desejada. Keohane (1982) defende que as escolhas no sistema internacional serão influenciadas de maneira a conferir maior peso às preferências dos atores mais poderosos. Benjamin Cohen (1982) nota que os regras e os arranjos institucionais específicos das instituições de Bretton Woods refletem mais as preferências dos Estados Unidos do que as da Grã-Bretanha. Jervis (1982) aponta que estados mais fracos tiveram poucas opções além de seguir o equilíbrio de poder do século XIX, com sua ênfase no papel especial das grandes potências. Em todos esses casos, os atores mais poderosos criaram regimes que serviram aos seus propósitos particulares; os outros atores foram levados a aceitá-los porque seus ganhos foram manipulados ou suas opções eram limitadas.

Quando um Estado hegemônico age para influenciar a estratégia de outros atores o regime fica refém da persistência da distribuição de poder existente no sistema internacional. Se a capacidade relativa desse Estado hegemônico declina, o regime entra em colapso. Young (1982) argumenta que ordens internacionais impostas são mais propensas a desintegrarem-se quando ocorrem fortes mudanças nas capacidades de poder que estão na base do regime. Puchala e Hopkins (1982) sugerem que regimes altamente politizados, difusos e tendenciosos na sua distribuição de valores são propensos a entrar em transformação radical quando muda a distribuição de poder. Por exemplo, as normas do regime colonial entraram em colapso porque o poder das potências que o sustentavam - os principais estados europeus - erodiu-se. Esse conjunto de argumentos sobre mudança de regime e declínio hegemônico difere da análise com foco no fornecimento de bens coletivos tanto por motivos cosmopolitas quanto por motivos particularistas. Nestes últimos casos, o declínio de poder leva a mudanças de regime porque o Estado hegemônico não é mais capaz de controlar o padrão de ganhos ou de influenciar as estratégias dos estados fracos - e não porque inexista um ator capaz de fornecer os bens coletivos necessários para o funcionamento eficiente do regime.

\section{IV.3. Normas e princípios}

Até este momento, as normas e os princípios foram tratados como endógenos: eles são as características críticas definidoras de qualquer regime. Entretanto, as normas e os princípios que influenciam o regime de determinada área das relações internacionais, mas que não estão diretamente relacionados a essa área, também podem ser considerados como explicações para a criação, a persistência e a dissipação de regimes. O exemplo mais famoso dessa formulação é $A$ ética protestante e o espírito do capitalismo de Max Weber. Weber argumenta que o surgimento do capitalismo está intimamente associado ao desenvolvimento da doutrina religiosa calvinista que favorece o trabalho árduo em vez do desperdício e que tem como indício de predestinação o sucesso mundano ${ }^{12}$. Fred Hirsch argumentou que sem os valores pré-capitalistas, tais como o trabalho árduo, o auto-sacrifício, a lealdade e a honra, o sistema capitalista desmoronaria. Tais valores são restrições cruciais aos cálculos auto-interessados que muito freqüentemente conduzem a comportamentos indignos de confiança e desonestos (HIRSCH, 1976, cap. 11; cf. também WALZER, 1980).

12 Para uma discussão recente, vide Laitin (1978, especialmente p. 568-569). Para uma outra discussão sobre valores não-econômicos no surgimento do capitalismo, cf. Hirschman (1977). 
As formas de financiamento de diversos grupos párias ao redor do mundo oferece um claro exemplo de como normas não-econômicas facilitaram as atividades de mercado. Por exemplo, as letras de câmbio foram inventadas por banqueiros judeus no fim da Idade Média para evitar a violência e a extorsão praticadas pela nobreza: era mais seguro carregar um pedaço de papel que dinheiro em espécie. Entretanto, o pedaço de papel precisava ser honrado pelo seu recebedor. Isso implicava um alto nível de confiança, o qual era realçado pelas convenções: as práticas estabelecidas eram reforçadas pela exclusão social sofrida pelo grupo, o que facilitava a supervisão e a aplicação de sanções. A importância das convenções para o uso das letras de câmbio reflete-se no fato de que as estas eram freqüentemente usadas na bacia do Mediterrâneo no século XVI, mas não eram usadas na interação com o mundo não-mediterrâneo na Síria, onde, conforme Braudel (1975, p. 370), “dois mundos com suspeitas mútuas encontravam-se face a face". Na Síria, todas as negociações eram feitas com base em permutas, ouro ou prata ${ }^{13}$.

Nesta edição, Puchala e Hopkins (1982) fazem uma distinção entre a superestrutura e a subestrutura. A superestrutura refere-se a princípios e normas gerais e difundidos que condicionam os princípios e normas operativos em uma determinada área temática. Os autores apontam, por exemplo, que o equilíbrio de poder no século XIX na Europa era uma norma disseminada que influenciou a natureza do regime colonial. Jervis argumenta que, para os regimes desenvolverem-se na área de segurança, as grandes potências "precisam acreditar que os demais compartilham os valores por elas promovidos em segurança mútua e cooperação" (JERVIS, 1982, p. 361). Em sua análise altamente original sobre o do regime econômico do período posterior à II Guerra Mundial, John Ruggie (1982) argumenta que esse regime foi fundado mais propriamente em princípios do liberalismo incrustado [embedded liberalism] do que do liberalismo ortodoxo. A lição doméstica dos anos 1930 foi que as sociedades não poderiam tolerar as conseqüências de um mercado sem controles. Esse conjunto de valores difusos, que permeava

13 Para a ligação entre letras de câmbio e banqueiros judeus, cf. Wallerstein (1974, p. 147) e Hirschman (1977, p. 72). o mundo capitalista, estendeu-se da esfera doméstica para a internacional nos acordos de Bretton Woods.

A presente discussão sugere que existe uma hierarquia de regimes. Os princípios e as normas disseminados pelo regime - tais como o trabalho árduo a serviço de deus - condicionam o comportamento em determinadas áreas temáticas. Nas relações internacionais, o mais importante princípio disseminado é a soberania. Hedley Bull refere-se à soberania como o princípio constitutivo do atual sistema internacional. Os conceitos de controle exclusivo no interior de uma determinada área geográfica e do direito indiscutível de autoajuda nas relações internacionais surgiram no final da Idade Média e passaram a permear o sistema internacional moderno (BULL, 1977, p. 8-9, 70).

Nesse sentido, a soberania não é uma conjectura analítica, mas um princípio que influencia o comportamento dos atores. Com as poucas exceções de Antártica, Namíbia e Cisjordânia ${ }^{14}$, a soberania prevalece. Essas áreas em que a soberania não se aplica são ou

14 Alguns esclarecimentos históricos e políticos são necessários aqui.

A Antártica é regida pelo Tratado Antártico, assinado em 1959 e renovado em 1991 até, pelo menos, 2041; de acordo com ele, o continente gelado é patrimônio de toda a humanidade, ou seja, nenhum país detém a soberania sobre ele. Além disso, a exploração comercial e a sua militarização são proibidas; somente pesquisas científicas são permitidas. Apesar disso, diversos países postulam direitos territoriais ou reservam-se a possibilidade de reclamar tais direitos, como a Argentina, a Austrália, o Chile e mesmo várias nações do Hemisfério Norte (Inglaterra, França, Noruega, Estados Unidos, Rússia).

No que se refere à Namíbia, antes de mais nada convém notar que o presente artigo é de 1982. Antiga colônia alemã, após a I Guerra Mundial o território da Namíbia tornouse um protetorado da Liga das Nações; tal situação não se manteve com a Organização das Nações Unidas (ONU), após a II Guerra Mundial. Com isso, a partir de 1946 a Namíbia passou a ser controlada pela África do Sul, em uma situação de facto; por fim, em 1990 ela tornou-se uma nação soberana.

A Cisjordânia (ou West Bank, em inglês) é um território que fica a Oeste do rio Jordão, entre Israel e a Jordânia. Em 1948, com a criação de Israel e a anuência da antiga potência colonial da região (a Grã-Bretanha), nesse território deveria constituir-se um Estado palestino; todavia, em 1967, devido à Guerra dos Seis Dias, essa região foi ocupada militarmente por Israel, que desde então controla de facto as suas fronteiras (N. T.) 
governadas por regimes vulneráveis ou sofrem da total falta de regimes. A soberania define que os estados são os únicos atores com direitos ilimitados de ação no sistema internacional. Declarações de outras agências são sujeitas a desafios. Se o princípio constitutivo da soberania fosse alterado, seria difícil imaginar que qualquer outro regime internacional permanecesse inalterado.

\section{IV.4. Usos e costumes}

Os últimos dois tipos de variáveis causais que afetam o desenvolvimento de regimes são os usos e costumes e o conhecimento. Os usos e costumes serão discutidos nesta seção e o conhecimento na seguinte. Os usos e costumes e conhecimento não são vistos nesta edição como varáveis exógenas capazes de gerar regimes por si mesmas. Ao contrário, eles sustentam e reforçam as pressões associadas ao auto-interesse egoísta, ao poder político e aos valores disseminados.

$\mathrm{O}$ uso refere-se aos padrões regulares de comportamento baseados na prática efetiva; o costume, às práticas existentes há longo tempo (WEBER, 1977, p. 29). A importância do comportamento rotinizado é particularmente significativa nas visões de Puchala e Hopkins (1982) e Young (1982). Para esses autores, o comportamento padronizado, gerado originalmente por puras considerações de interesse ou poder, tem uma forte tendência a gerar expectativas compartilhadas. É provável que o comportamento padronizado acompanhado de expectativas compartilhadas assuma um significado normativo: as ações baseadas puramente em cálculos instrumentais podem ser consideradas como comportamentos baseados em regras ou princípios. Esses comportamentos ganham legitimidade. De fato, uma grande parcela do Direito Comercial ocidental desenvolveu-se a partir de usos e costumes gerados inicialmente por interesses próprios. As práticas que começaram como arranjos privados ad hoc mais tarde se tornaram a base do Direito Comercial oficial (BERMAN \& KAUFMAN, 1978; TRAKMAN, 1980; 1981).

$\mathrm{Na}$ discussão de Oran Young (1982) sobre regimes espontâneos e impostos, os usos e costumes têm papel significativo. Young não faz grandes reivindicações sobre as condições específicas que criam regimes espontâneos.
Entretanto, a literatura à qual ele refere-se Schelling, Lewis e Hayek - tem uma perspectiva microeconômica focada no auto-interesse egoísta. Alguns padrões de comportamento são inicialmente adotados porque promovem a utilidade individual. Uma vez estabelecidas, tais práticas são reforçadas pelo crescimento dos regimes. A maioria dos motoristas estadunidenses (fora da cidade de Nova York) sentiria no mínimo uma ponta de desconforto ao atravessar ilegalmente um semáforo vermelho em um cruzamento vazio. O comportamento que no começo era apenas uma questão de auto-interesse egoísta é agora reforçado por normas amplamente compartilhadas. De maneira similar, Young (1982) argumenta que as ordens impostas com sucesso finalmente são sustentadas por hábitos de obediência. (Não está claro se, sem esses hábitos, o conceito de Young de ordens impostas atende à definição de regime usada nesta edição.) Um padrão de comportamento inicialmente estabelecido via coerção econômica ou pela força pode ser visto como legítimo por aqueles sobre os quais o padrão foi imposto. O uso leva a expectativas compartilhadas, que se difundem como princípios e normas.

\section{IV.5. Conhecimento}

A última variável utilizada para explicar o desenvolvimento de regimes é o conhecimento. Assim como os usos e costumes, o conhecimento é normalmente tratado como uma variável interveniente e não como uma variável exógena. Em um estudo anterior, Ernest Haas - o defensor mais destacado nesta edição da importância do conhecimento - definiu o conhecimento como "a soma da informação técnica e das teorias a respeito dessa informação que gera um consenso pleno em um determinado momento entre os atores interessado e cujo objetivo é servir como guia para que políticas públicas alcancem alguma meta social" (HAAS, 1980a, p. 367-368). Em seu artigo desta edição, Haas demonstra as potencialidades inerentes a uma postura de "evolucionismo cognitivo", que enfatiza a sensibilidade para com as conseqüências da geração de novos conhecimentos. O conhecimento cria uma base para a cooperação ao destacar as interconexões complexas que não eram previamente entendidas. $\mathrm{O}$ conhecimento pode não somente acentuar as possibilidades de comportamento estatais convergentes, como também transcender as "linhas predominantes de 
clivagem ideológica" (idem, p. 368). Além disso, o conhecimento pode propiciar uma base comum tanto para aquilo que Haas chama de "abordagens mecânicas" (as teorias sociais mais convencionais) como para o que o autor chama de "abordagens orgânicas" (o igualitarismo e diversas perspectivas ambientalistas).

Para o conhecimento ter um impacto autônomo no sistema internacional, ele deve ser amplamente aceito pelos tomadores de decisões. Stein (1982) aponta que as regras relativas à saúde - como os regulamentos de quarentena - foram radicalmente alteradas por novos conhecimentos científicos, tais como o uso de vacinas preventivas e as descobertas do micróbio que causa a cólera e do mecanismo de transmissão da febre amarela por mosquitos. Antes de descobertas como essas, as regras nacionais de saúde eram primordialmente definidas por preocupações políticas. Entretanto, após tais descobertas, o comportamento nacional passou a ser determinado por um regime internacional, ou pelo menos por um conjunto de regras ditadas pelo conhecimento cientifico reconhecido. Jervis (1982) argumenta que na presente arena de segurança internacional, as possibilidades de um regime de controle de armas podem depender de se a União Soviética e os Estados Unidos vêem a questão da mesma forma. Em particular, a aceitação da destruição mútua assegurada $^{15}$ pode prover as bases para um regime. Sem consenso, o conhecimento pode ter pouco impacto no desenvolvimento de regimes em um mundo de estados soberanos. Se apenas algumas partes compartilharem um conjunto específico de crenças, sua importância será totalmente mediada pelo poder de seus seguidores.

O novo conhecimento pode fornecer a base para aquilo que Puchala e Hopkins (1982) chamam de "mudança evolucionária", a qual normalmente envolve alterações de regras e procedimentos no

${ }^{15}$ A "destruição mútua assegurada" é conhecida em inglês por "mutual assured destruction" ou, ainda, por sua sigla "MAD", ou seja, "louco". O raciocínio subjacente à "destruição mútua assegurada" é o seguinte: em um ambiente internacional anárquico caracterizado pelas difusão das armas nucleares, caso um país decida lançar suas bombas sobre outro que também possua bombas nucleares, a resposta será imediata e retaliatória, de tal modo que a destruição mútua será garantida. Como, aliás, tal cenário, embora possível, é política e humanamente problemático, justifica-se o acrônimo "mad" (N. T.) contexto de um dado conjunto de princípios e normas. Em contraste, a "mudança revolucionária", que gera novos princípios e normas, é associada a variações de poder. Como exemplo de mudança evolucionária, Benjamin Cohen (1982) indica que o sistema de taxa de câmbio fixa acordado em Bretton Woods baseouse em entendimentos oriundos da experiência do período entre guerras e do conhecimento da época sobre instituições e estruturas monetárias domésticas. Os estados eram extremamente sensíveis à desvalorização competitiva e não confiavam que as políticas monetárias domésticas pudessem prover um isolamento em relação aos distúrbios externos. Por outro lado, foi muito mais fácil aceitar o regime de taxa de câmbio flutuante nos anos 1970, pois o conhecimento e a capacidade institucional correlata para controlar a moeda haviam melhorado substancialmente. Em um mundo altamente complexo, em que as metas são freqüentemente mal definidas e muitas conexões são possíveis, o conhecimento consensual pode facilitar imensamente os acordos para o desenvolvimento de regimes internacionais. Esse conhecimento pode iluminar um caminho em um ambiente que de outra forma seria obscuro e indiscernível.

Em suma, os artigos desta edição e a literatura em geral oferecem uma diversidade de explicações para o desenvolvimento de regimes. As duas variáveis exógenas mais destacadas são o autointeresse egoísta (normalmente econômico) e o poder político. Além disso, os valores e as normas disseminados, tais como a soberania e a propriedade privada, podem condicionar o comportamento em determinadas áreas temáticas. Finalmente, os usos e costumes e o conhecimento podem contribuir para o desenvolvimento de regimes.

\section{CONCLUSÃO}

Ao abordar as duas questões básicas que guiaram este exercício teórico - o impacto dos regimes sobre os correspondentes comportamentos e resultados, por um lado, e a relação entre as variáveis causais básicas e os regimes, por outro lado - os artigos desta edição refletem duas visões diferentes das relações internacionais. A perspectiva grociana, observada nos artigos de Puchala e Hopkins (1982) e Young (1982), vê os regimes como uma faceta disseminada da interação social. Essa abordagem 
é ampla na descrição das causas fundamentais dos regimes: interesse, poder, normas difundidas, costumes e conhecimento podem ter relevância na formação de um regime. Esses fatores causais podem manifestar-se por meio do comportamento de indivíduos, de burocracias específicas e das organizações internacionais, assim como dos estados.

A orientação realista estrutural que permeia os demais artigos desta edição é mais circunspecta. O caso exemplar ou padrão da perspectiva realista não inclui os regimes internacionais. Os regimes surgem apenas em condições restritas caracterizadas pela falha na tomada de decisão individual em assegurar os resultados desejados. As variáveis causais básicas que levam à criação dos regimes são o poder e o interesse. Os atores básicos são os estados.

Os argumentos apresentados por Cohen (1982), Jervis (1982), Keohane (1982), Lipson (1982), Ruggie (1982) e Stein (1982), de fato vão além das orientações realistas convencionais. Eles rejeitam uma análise estrutural estreita que, por um lado, postula uma relação direta entre mudanças em variáveis causais básicas e os correlatos comportamentos e resultados e que, por outro lado, nega a utilidade do conceito de regime. Por isso eles são criticados por Susan Strange (1982). Entretanto, as restrições paramétricas básicas dessas análises são idênticas àquelas utilizadas pelos argumentos estruturalistas mais convencionais. Os pressupostos analíticos básicos são os mesmos. As abordagens que tratam os regimes como variáveis intervenientes e consideram os interesses e poder do Estado como variáveis causais básicas encaixam-se sem ambigüidades no paradigma realista estrutural. Uma abordagem mais séria do raciocínio estruturalista ocorre quando os regimes são vistos como variáveis autônomas que afetam independentemente não apenas os comportamentos e resultados correlatos, como também as variáveis causais básicas que conduziram inicialmente à sua criação. Essa linha de raciocínio é examinada na conclusão deste volume.

Stephen D. Krasner (skrasner@stanford.edu) é Doutor em Ciência Política pela Universidade de Harvard (Estados Unidos) e Professor da Universidade de Stanford (Estados Unidos).

\section{REFERÊNCIAS BIBLIOGRÁFICAS}

AGGARWAL, V. K. 1981. Hanging by a Thread: International Regime Change in the TextileApparel System, 1950-1979. PhD Thesis. Stanford: Stanford University.

BELSHAW, C. 1965. Traditional Exchange and Modern Markets. Englewood Cliffs: PrenticeHall.

BERMAN, H. \& KAUFMAN, C. 1978. The Law of International Commercial Transactions (Lex Mercatoria). Harvard International Law Journal, Boston, v. 19, n. 1, Winter.

BILLET, L. 1974. The Just Economy: The Moral Basis of the Wealth of Nations. Review of Social Economy, London, v. 34, n. 3, p. 295-315, Dec.

BRAUDEL, F. 1975. The Mediterranean and the Mediterranean World in the Age of Philip II. New York: Harper.

BULL, H. 1977. The Anarchical Society: A Study of Order in World Politics. New York: Columbia University.
COHEN, B. J. 1982. Balance-of-Payments Financing: Evolution of a Regime. International Organization, Cambridge (MA), v. 36, n. 2, p 457-478, Spring.

DIAZ-ALEJANDRO, C. 1978. Delinking North and South: Unshackled or Unhinged. In: FISHLOW, A. (ed.). Rich and Poor Nations in the World Economy. New York: McGraw-Hill.

HAAS, E. B. 1980a. Why Collaborate? IssueLinkage and International Regimes. World Politics, Washington (DC), v. 32, n. 3, p. 357405, Apr.

1980b. Technological Self-Reliance for Latin America: The OAS Contribution. International Organization, Cambridge (MA), v. 34, n. 4, p. 541-570, Autumn.

. 1982. Words Can Hurt You; Or, Who Said What To Whom about Regimes. International Organization, Cambridge (MA), v. 36, n. 2, p 207-243, Spring. 
HIRSCH, F. 1976. The Social Limits to Growth. Cambridge (MA): Harvard University.

HIRSHLEIFER, J. 1977. Economics from a Biological Viewpoint. Journal of Law and Economics, Chicago, v. 20, n. 1, p. 1-52, Apr.

HIRSCHMAN, A. 1977. The Passions and the Interests. Political Arguments for Capitalism before Its Triumph. Princeton: Princeton University.

HOLMES, C. 1976. Laissez-Faire in Theory and Practice: Britain 1800-1875. Journal of European Economic History, v. 5, n. 3.

JERVIS， R. 1982. Security Regimes. International Organization, Cambridge (MA), v. 36, n. 2, p. 357-378, Spring.

KAPLAN, M. 1957. Systems and Process in International Politics. New York: Wiley.

1979. Towards Professionalism in International Theory. New York: Free.

KEOHANE, R. O. 1980. The Theory of Hegemonic Stability and Changes in International Economics Regimes, 1967-77. In: HOLSTI, O. R. (ed.). Changes in the International System. Boulder: Westview.

1982. The Demand for International Regimes. International Organization, Cambridge (MA), v. 36, n. 2, p. 325-355, Spring.

KEOHANE, R. O. \& NYE, J. S. 1977. Power and Independence. Boston: Little, Brown.

KINDLEBERGER, C. P. 1978a. Government and International Trade. Princeton: Princeton University.

1978b. Manias, Panics, and Clashes: A History of Financial Crisis. New York: Basic.

KUHN, T. 1970. The Structure of Scientific Revolutions. $2^{\text {nd }}$ ed. Chicago: University of Chicago.

LAITIN, D. 1978. Religion, Political Culture, and the Weberian Tradition. World Politics, Washington (DC), v. 30, n. 4, p. 563-592, July.

LIJPHART, A. 1974. The Structure of the Theoretical Revolution in International Relations. International Studies Quarterly, London, v. 18, n. 1, p. 41-74, Mar.
LIPSON, C. 1982. The Transformation of Trade: The Sources and Effects of Regime Change. International Organization, Cambridge (Mass.), v. 36, n. 02, p. 417-455, Spring.

NORTH, D. C. \& THOMAS, R. P. 1973. The Rise of the Western World: A New Economic History. Cambridge (UK): Cambridge University.

PUCHALA, D. J. \& HOPKINS, R. F. 1982. International Regimes: Lessons from Inductive Analysis. International Organization, Cambridge (MA), v. 36, n. 2, p. 245-275, Spring.

ROSECRANCE, R. 1981. International Theory Revisited. International Organization, Cambridge (MA), v. 35, n. 4, p. 691-713, Autumn.

RUGGIE, J. G. 1982. International Regimes, Transactions, and Change: Embedded Liberalism in the Postwar Economic Order. International Organization, Cambridge (MA), v. 36 , n. 2, p. 379-415, Spring.

STEIN，A. A. 1982. Coordination and Collaboration: Regimes in An Anarchic World. International Organization, Cambridge (MA), v. 36, n. 2, p. 299-324, Spring.

STRANGE, S. 1982. Cave! Hic Dragones: A Critique of Regime Analysis. International Organization, Cambridge (MA), v. 36, n. 2, p. 479-496, Spring.

TOULMIN, S. 1961. Foresight and Understanding: An Enquiry into the Aims of Science. New York: Harper Torchbooks.

TRAKMAN, L. E. 1980. The Evolution of the Law Merchant: Our Commercial Heritage. Part I. Journal of Maritime Law and Commerce, v. 12 , n. 1 , Oct.

1981. The Evolution of the Law Merchant: Our Commercial Heritage. Part II. Journal of Maritime Law and Commerce, v. 12, n. 2, Jan.

WALLERSTEIN, I. 1974. The Modern WorldSystem. New York: Academic.

WALTZ, K. 1979. Theory of International Relations. Reading (MA): Addison-Wesley.

WALZER, M. 1980. The New Masters. Review of the books The Intellectuals on the Road to 
Class Power by George Konrád and Ivan Szelényi, and The Future of Intellectuals and the Rise of the New Class by Alvin W. Gouldner. New York Review of Books, v. 27, n. 4, March $20^{\text {th. }}$.
WEBER, M. 1977. Economy and Society. Berkley: University of California.

YOUNG, O. 1982. Regime Dynamics: The Rise and Fall of International Regimes. International Organization, Cambridge (MA), v. 36, n. 2, p. 277-297, Spring. 
STRUCTURAL CAUSES AND REGIME CONSEQUENCES: REGIMES AS INTERVENING VARIABLES

\section{Stephen D. Krasner}

Abstract: International regimes are defined as principles, norms, rules and decision making procedures around which actor expectations converge in a given issue area. As a starting point, regimes have been conceptualized as intervening variables, standing between basic causal factors and related outcomes and behaviour. There are three views about the importance of regimes: conventional structural orientations dismiss regimes as being at best ineffectual; Grotian orientations view regimes as an intimate component of the international system; and modified structural perspectives see regimes as significant only under certain constrained conditions. For Grotian and modified structuralist arguments, which endorse the view that regimes can influence outcomes and behavior, regime development is seen as a function of five basic causal variables: egoistic self interest, political power, diffuse norms and principles, custom and usage, and knowledge

KEYWORDS: International Regimes; Intervening Variables; Behavior; Grotianism; Modified Structuralism. 


\section{LES CAUSES STRUCTURELLES ET LES CONSÉQUENCES DES RÉGIMES INTERNATIONAUX : LES RÉGIMES COMME DES VARIABLES INTERVENANTES}

\section{Stephen D. Krasner}

Les régimes internationaux sont définis comme des principes, normes, règles et procédures de prise de décisions autour desquels les expectatives des auteurs se dirigent vers un certain domaine et thème. Comme point de départ, les régimes sont considérés comme des variables intervenantes, étant entre des facteurs causaux basiques et les résultats et comportements liés à eux. Il y a trois visions par rapport à l'importance des régimes : les orientations structurelles conventionnelles dévalorisent les régimes comme étant, dans la meilleure hypothèse, inefficaces ; les orientations grotiennes voient les régimes comme des composants intimes du système international; les perspectives structuralistes modifiées ne voient les régimes comme étant significatifs que dans certaines conditions restreintes. Pour les arguments grotiens et structuraliste modifié - qui sont d'accord avec la vision selon laquelle les régimes peuvent influencer des résultats et des comportements -, le développement de régimes est vu comme une fonction de cinq variables causales fondamentales : intérêt égoïste ; pouvoir politique ; normes et principes diffus ; usages et habitudes ; connaissance.

MOTS-CLÉS: régimes internationaux ; variables intervenantes ; comportement ; grotianisme; structuralisme modifié. 